\title{
Population-Based Serosurvey for Severe Acute Respiratory Syndrome Coronavirus 2 Transmission, Chennai, India
}

\author{
Sriram Selvaraju, Muthusamy Santhosh Kumar, Jeromie Wesley Vivian Thangaraj, Tarun Bhatnagar, \\ Velusamy Saravanakumar, Chethrapilly Purushothaman Girish Kumar, Krithikaa Sekar, \\ Ezhilarasan Ilayaperumal, Ramasamy Sabarinathan, Murugesan Jagadeesan, Masanam \\ Sriramulu Hemalatha, Manoj Vasant Murhekar, and the Chennai COVID Sero-Surveillance Team
}

We conducted a cross-sectional survey to estimate the seroprevalence of IgG against severe acute respiratory syndrome coronavirus 2 in Chennai, India. Among 12,405 serum samples tested, weighted seroprevalence was $18.4 \%$ $(95 \% \mathrm{Cl} 14.8 \%-22.6 \%)$. These findings indicate most of the population of Chennai is still susceptible to this virus.

O August 15, 2020, India had the third highest number of coronavirus disease (COVID-19) cases globally (1). The Indian state of Tamil Nadu reported 332,105 cases and 5,641 deaths on August 15, and $\approx 35 \%$ cases were from the state capital, Chennai (2). Administratively, Greater Chennai Corporation (GCC) is divided into 15 zones that are further divided into 200 wards with populations ranging from $4,400-104,558$ (3). The total population of GCC is 7.1 million and $31 \%$ of the population resides in slums.

As a part of nationwide containment strategy, Chennai was under lockdown beginning March 25, 2020; beginning May 4, the lockdown was relaxed in a phased manner. Wearing facemasks in public has been mandatory since April 13. However, the number of COVID-19 cases has been increasing in Chennai since May.

Serologic surveys can provide a comprehensive picture of community spread of severe acute

\footnotetext{
Author affiliations: Indian Council of Medical Research-National Institute for Research in Tuberculosis, Chennai, India

(S. Selvaraju, K. Sekar, E. Ilayaperumal); ICMR-National Institute of Epidemiology, Chennai (M. Santhosh Kumar, J.W. Vivian Thangaraj, T. Bhatnagar, V. Saravanakumar, C.P. Girish Kumar, R. Sabarinathan, M.V. Murhekar); Greater Chennai Corporation, Chennai (M. Jagadeesan, M.S. Hemalatha)
}

DOI: https://doi.org/10.3201/eid2702.203938 respiratory syndrome coronavirus 2 (SARS-CoV-2), the causative agent of COVID-19 (4). During the first week of May, the unweighted seroprevalence in Chennai was $2 \%$ (5). We conducted a communitybased serosurvey in July 2020, to estimate the seroprevalence of SARS-CoV-2 in GCC.

\section{The Study}

We conducted a household-based cross-sectional survey among usual residents $\geq 10$ years of age in GCC. To estimate a seroprevalence of $2 \%$, with $20 \%$ relative precision, design effect of 2.5 , and $95 \% \mathrm{CI}$, we needed a sample size of 11,710 persons, which we rounded to 12,000 . We used a multistage cluster sampling method to select the survey participants. In the first stage, we selected 51 wards by using probability proportion to population size method. In the second stage, we randomly selected 6 streets from each ward from which to recruit participants. The survey team selected a random starting point in each street and visited contiguous households to enroll $\geq 40$ consenting persons $\geq 10$ years of age. When no one was home or household members were unavailable, the team proceeded to the next house and completed the survey until $\geq 40$ persons were enrolled from each street. We included all eligible persons in the household who consented.

After obtaining written consent from persons $\geq 18$ years of age, and assent and parental or guardian approval from persons $<18$ years of age, we interviewed participants to collect information. We used the Open Data Kit application (https:/ / opendatakit.org) to collect sociodemographic details, and information on exposure to laboratory-confirmed COVID-19 case, history of COVID-19 symptoms in the past 3 months, and COVID-19 testing status. 
After the interview, we collected $3-5 \mathrm{~mL}$ of venous blood from each participant into BD Vacutainer Blood Collection Tubes (Becton Dickenson, https:/ / www.bd.com). We later tested serum samples for IgG against SARS-CoV-2 by using SARS-CoV-2 IgG immunoassay (Abbott, https://www.corelaboratory. abbott) (Appendix, https://wwwnc.cdc.gov/EID/ article/27/2/20-3938-App1.pdf) (6). The study protocol was approved by the Institutional Ethics Committee of ICMR-National Institute of Epidemiology.

We analyzed the data to estimate weighted seroprevalence of SARS-CoV-2 and 95\% CI by using appropriate sampling weights. We further adjusted the seroprevalence for assay characteristics (6). We estimated the total number of SARS-CoV-2 infections among persons $\geq 10$ years of age and infection-to-case ratio (ICR) (Appendix).

The survey teams visited 7,234 households from 321 streets across 15 zones. Of the 18,040 residents $\geq 10$ years of age in the visited households, 14,839 (82.3\%) were available at the time of survey, among whom $12,405(83.6 \%)$ consented to participate (Appendix Table 1). The mean age of survey participants was 41.1 years (SD 17.3 years); $52.7 \%$ were female and $47.3 \%$ were male. Among 496 (4\%) persons who reported prior reverse transcription-PCR (RT-PCR) testing for COVID-19, 119 (24\%) reported testing positive (Table 1).

Among 12,405 serum samples tested, 2,673 were positive for IgG , a weighted prevalence of $18.7 \%$ (95\% CI $15.1 \%-22.9 \%$ ). After adjusting for the test sensitivity and specificity, seroprevalence was $18.4 \%$ (95\% CI $14.8 \%-22.6 \%$ ) (Table 2). The weighted seroprevalence was higher among female participants $(20.6 \%$, 95\% CI $16.7 \%-25.3 \%)$ than male participants $(16.6 \%, 95 \%$ CI 13.2\%-20.6\%) $(\mathrm{p}<0.001)$. Weighted seroprevalence was lowest among persons $\geq 60$ years of age $(13.4 \%$, $95 \%$ CI $10.3 \%-17.4 \%)$ than younger persons $(\mathrm{p}=$ 0.001) (Table 2). We retested 100 seronegative and 40 seropositive samples and results were concordant.

From our data, we estimated a total of $1,509,701$ (95\% CI 1,212,711-1,856,190) SARS-CoV-2 infections in Chennai. ICR per laboratory-confirmed case was 21.4 (95\% CI 17.2-26.3) until July 7 and 19.2 (95\% CI 15.4-23.6) until July 14, 2020.

\section{Conclusions}

Our community-based survey indicated that $\approx 1 / 5$ persons in Chennai was exposed to SARS-CoV-2 by July 2020. We noted a wide variation in the extent of infection across wards and seroprevalence ranged from $2 \%-50 \%$ (Appendix Table 3).

Seroprevalence was higher in northern Chennai and adjoining wards of central Chennai than in

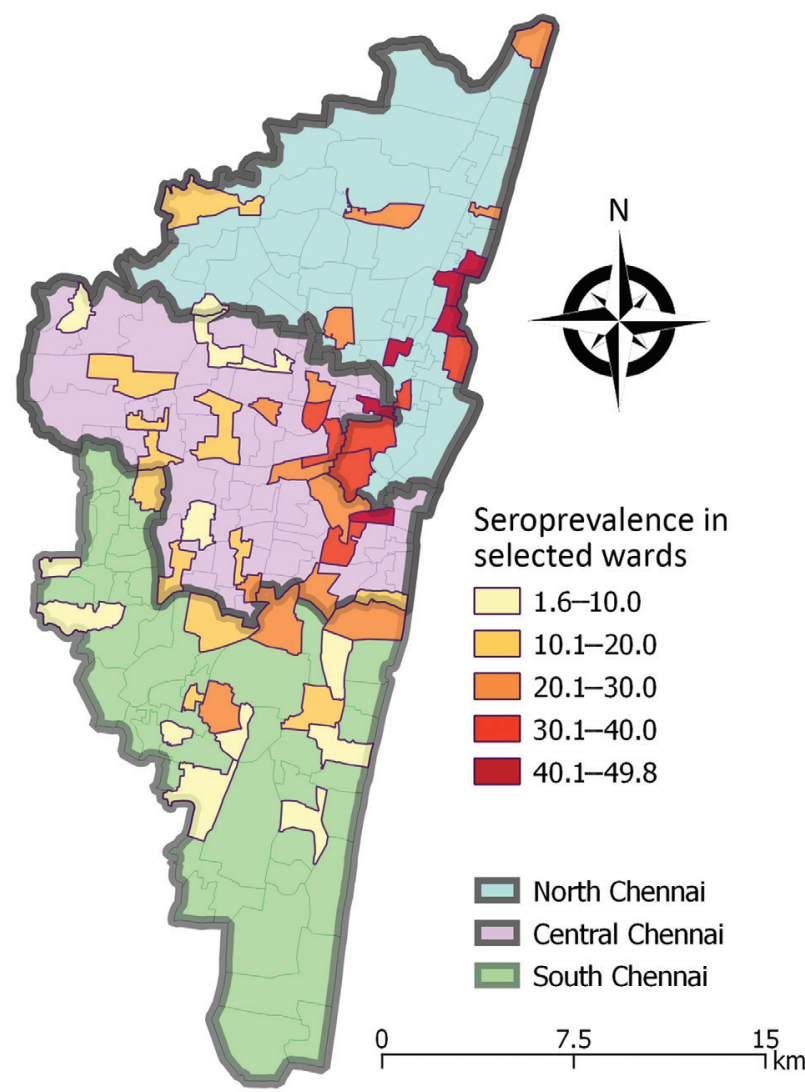

Figure. Seroprevalence of SARS-CoV-2 among residents of Chennai, India, July 2020. Values represent percent seroprevalence. SARS-CoV-2, severe acute respiratory syndrome coronavirus 2.

southern Chennai (Figure). Chennai witnessed a surge in COVID-19 cases in last week of April 2020 and $>65 \%$ of cases were in northern Chennai (7). The number of cases showed a declining trend after the first week of July. Northern Chennai has a higher population density $\left(55,000 / \mathrm{km}^{2}\right)$ than Chennai $(27,000 /$ $\mathrm{km}^{2}$ ) and has several slum areas (7). High population density and persons living in close proximity might have contributed to the higher seroprevalence observed in northern Chennai.

Seroprevalence was lower among male participants. Laboratory surveillance data in India showed a higher proportion of laboratory-confirmed COVID-19 among male than female patients (8). Comparable seroprevalence between children and adults suggests exposure within and outside of the household settings. Lower prevalence among persons $\geq 60$ years of age could be due to lower exposure to infected persons or stricter adherence to nonpharmaceutical interventions. Serosurveys conducted in Santa Clara County, California, USA reported lower seropositivity among persons $\geq 60$ years of age (E. Bendavid, 
Table 1. Characteristics of 12,405 participants in a SARS-CoV-2 serosurvey, Chennai, India, July 2020*

\begin{tabular}{lc}
\hline Characteristics & No. $(\%)$ \\
\hline Age, $\mathrm{y}, \mathrm{n}=12,319$ & $1,473(12.0)$ \\
$10-19$ & $2,105(17.1)$ \\
$20-29$ & $2,353(19.1)$ \\
$30-39$ & $2,353(19.1)$ \\
$40-49$ & $1,927(15.6)$ \\
$50-59$ & $2,108(17.1)$ \\
$\geq 60$ & $5,785(47.0)$ \\
\hline Sex, $\mathrm{n}=12,319$ & $6,493(52.7)$ \\
$\mathrm{M}$ & $41(0.3)$ \\
$\mathrm{F}$ & $175(1.4)$ \\
$\quad$ Transgender & $121(69.1)$ \\
\hline History of respiratory symptoms, $\mathrm{n}=12,248$ & $71(58.7)$ \\
Symptomatic persons seeking medical care, & \\
$\mathrm{n}=175$ & $173(1.4)$ \\
Hospitalization among persons seeking & \\
medical care, $\mathrm{n}=121$ & \\
Reported contact with COVID-19 case, \\
$\mathrm{n}=12,248$ & \\
\hline *Among 12,405 persons enrolled in the survey, age and sex data were not \\
available for 86 participants. COVID-19, coronavirus disease; SARS-CoV- \\
2, severe acute respiratory syndrome coronavirus 2. \\
\hline
\end{tabular}

et al. unpub. data, https:// doi.org/10.1101/2020.04.14. 20062463); however, in Spain, seropositivity was similar across all age groups (9) and in Greece, seroprevalence was higher among persons $\geq 60$ years of age (10).

Most seropositive participants in our survey did not report any symptoms nor had any known contact with COVID-19 patient. IgG developed among most $(107 / 119 ; 90 \%)$ recovered COVID-19 patients in our survey. Among 105 participants for whom $\geq 15$ days had passed between RT-PCR confirmation of COVID-19 and blood sample collection for our serosurvey, 99 (94.2\%) had seroconverted. Even after accounting for a 2-week delay for development of antibodies (11), $\approx 6 \%$ of COVID-19 patients were seronegative. Discordance between RT-PCR test results and presence of IgG might be due to poor B cell response or antibodies waning over time (12).

The ICR ranged from 19-21 and was lower than the ICR of 82-130 reported during the nationwide seroprevalence survey in India conducted in May 2020 (5). Lower ICR reflects a high level of case detection, resulting from extensive COVID-19 testing in the city. By July 15, 2020, Chennai had conducted 14,270 tests / million population.

Our study had 2 limitations. First, $\approx 1 / 3$ persons from the visited households did not participate in the survey. Among them, $17.7 \%$ were not available at the time of visit and $13.5 \%$ refused to participate. Due to time constraints, we did not revisit households where persons were not available. The proportion of female participants and children 10-19 years of age was higher among persons who did not participate in the survey (Appendix Table 2), which might have influenced the seroprevalence estimates in either direction. Second, we might have underestimated the seroprevalence because antibodies to

\begin{tabular}{|c|c|c|c|c|c|c|}
\hline Characteristics & $\begin{array}{c}\text { No. } \\
\text { tested }\end{array}$ & $\begin{array}{c}\text { No. } \\
\text { positive }\end{array}$ & $\begin{array}{c}\text { Unadjusted } \\
\text { seroprevalence, } \\
\%(95 \% \mathrm{Cl})\end{array}$ & $\begin{array}{c}\text { Weighted } \\
\text { seroprevalence, } \\
\%(95 \% \mathrm{Cl})\end{array}$ & $p$ value & $\begin{array}{c}\text { Test performance- } \\
\text { adjusted seroprevalence, } \\
\%(95 \% \mathrm{Cl})\end{array}$ \\
\hline Overall & 12,405 & 2,673 & $21.5(20.8-22.3)$ & $18.7(15.1-22.9)$ & NA & $18.4(14.8-22.6)$ \\
\hline \multicolumn{7}{|l|}{ Sex } \\
\hline $\mathrm{M}$ & 5,785 & 1,115 & $19.3(18.3-20.3)$ & $16.6(13.2-20.6)$ & $<0.001$ & $16.3(12.9-20.3)$ \\
\hline $\mathrm{F}$ & 6,493 & 1,538 & $23.7(22.7-24.7)$ & $20.6(16.7-25.3)$ & Referent & $20.3(16.4-25.0)$ \\
\hline Transgender & 41 & 5 & $12.2(4.1-26.2)^{\prime}$ & $2.8(0.2-27.6)$ & 0.093 & $2.4(0.0-27.3)$ \\
\hline \multicolumn{7}{|l|}{ Age, y } \\
\hline $10-19$ & 1,473 & 351 & $23.8(21.7-26.1)$ & $18.9(14.7-24.0)$ & Referent & $18.6(14.4-23.7)$ \\
\hline $20-29$ & 2,105 & 478 & $22.7(20.9-24.6)$ & $21.1(16.8-26.2)$ & 0.211 & $20.8(16.5-25.9)$ \\
\hline $30-39$ & 2,353 & 535 & $22.7(21.1-24.5)$ & $18.5(14.6-23.1)$ & 0.802 & $18.2(14.3-22.8)$ \\
\hline $40-49$ & 2,353 & 551 & $23.4(21.7-25.2)$ & $19.6(15.5-24.5)$ & 0.671 & $19.3(15.2-24.2)$ \\
\hline $50-59$ & 1,927 & 408 & $21.2(19.4-23.1)$ & $20.4(16.1-25.5)$ & 0.419 & $20.1(15.8-25.2)$ \\
\hline$\geq 60$ & 2,108 & 335 & $15.9(14.4-17.5)$ & $13.4(10.3-17.4)$ & 0.001 & $13.1(9.9-17.1)$ \\
\hline \multicolumn{7}{|c|}{ History of respiratory symptoms } \\
\hline Yes & 175 & 114 & $65.1(57.6-72.7)$ & $59.8(47.5-71.0)$ & $<0.001$ & $59.6(47.3-70.9)$ \\
\hline No & 12,073 & 2529 & $20.9(20.2-21.7)$ & $18.3(14.7-22.5)$ & Referent & $18.0(14.4-22.2)$ \\
\hline \multicolumn{7}{|c|}{ Contact with COVID-19 case } \\
\hline Yes & 173 & 94 & $54.3(46.6-61.9)$ & $45.3(34.6-56.6)$ & $<0.001$ & $45.1(34.3-56.4)$ \\
\hline No & 11,938 & 2,498 & $20.9(20.2-21.7)$ & $18.3(14.8-22.5)$ & Referent & $18.0(14.5-22.2)$ \\
\hline Don't know & 137 & 51 & $37.2(29.1-45.9)$ & $22.1(14.0-33.1)$ & 0.363 & $21.8(13.7-32.8)$ \\
\hline \multicolumn{7}{|c|}{ Ever tested for COVID-19 } \\
\hline Yes & 496 & 198 & $39.9(35.6-44.3)$ & $34.2(26.9-42.5)$ & $<0.001$ & $33.9(26.6-42.3)$ \\
\hline No & 11,752 & 2,445 & $20.8(20.0-21.6)$ & $18.0(14.6-22.1)$ & Referent & $17.7(14.3-21.8)$ \\
\hline \multicolumn{7}{|c|}{ COVID- 19 test result, $n=496$} \\
\hline Positive & 119 & 107 & $89.9(83.0-94.7)$ & NA & NA & NA \\
\hline Negative & 342 & 83 & $24.3(19.8-29.2)$ & NA & NA & NA \\
\hline Don't Know & 35 & 8 & $22.9(10.4-40.1)$ & NA & NA & NA \\
\hline
\end{tabular}

*COVID-19, coronavirus disease; NA, not applicable; SARS-CoV-2, severe acute respiratory syndrome coronavirus 2. 
nucleocapsid protein have been shown to decline after infection (13).

In conclusion, $\approx 80 \%$ of the population in Chennai is still susceptible to SARS-CoV-2 infection. Transmission is expected to continue in wards with lower seroprevalence. Maintaining high testing rates and monitoring adherence to nonpharmacological interventions in GCC should be continued. In addition, periodic serosurveys would help monitor the trend of infection and assess the effects of varying containment measures in the city.

This study was funded by Greater Chennai Corporation public health department (PHDC no. 2797/20 dated July 9, 2020).

\section{Acknowledgments}

We thank the Greater Chennai Corporation health officials for support in field operations. M.J. and M.S.H. are employees of Greater Chennai Corporation.

Chennai COVID Sero-surveillance team (in alphabetical order): Shravan Kumar Adavat, Akshitha, Vasudevan Arumugam, Ashwini, M. Balusamy, Chandrabalu, Sauvik Dasgupta, Tamil Mani Devi, Gomathi, R Gopinath, D. Gunasekaran, R. Harikrishnan, Satham Hussain, A. Jayakumar, Chitra Jayaprakash, Jayasree, Annamma Jose, I. Kalaimani, Kalayarasi, Anbarasan Kaliyappan, Bharath Kathavarayan, Krishna Yadav Kattagoni, T. Karunakaran, Maheshwari Krishnan, Ramesh Kumar Kumaraswamy, P. Ashok Kumar, K. Satish Kumar, Maheshkumar Madasamy, T. Magesh, Karthikesan Masilamani, A. Mohan, Rajesh Mondal, Murugesan, Nandhakumar, Kumaravel Padmanaban, R. Vijaya Prabha, C. Prabhakaran, Josephine Pradhan, E.B.Arun Prasath, G. Preethi, Michael Raj, Ranjithkumar, Rajmohan, K. Ramu, D. Sudha Rani, Catherine Rexy, N. Santhanakumar, S.Sarath Kumar, Anbalagan Selvaraj, Selvendiran, Sentrayan, Shalini, R. Sivakumar, Harshal Bhimrao Sonekar, A. Suresh, Suresh, Udhayakumar, V. Vettrichelvan, Hari Vignesh, and John Arokyadoss Yesuraj.

\section{About the Author}

Dr. Selvaraju is a scientist at ICMR-National Institute for Research in Tuberculosis, Chennai, India. His research interests include estimation of burden of tuberculosis and building laboratory, surveillance, and workforce capacity to detect, respond and prevent drug resistant tuberculosis in India.

\section{References}

1. World Health Organization. Coronavirus disease (COVID-19) situation report - 207 [cited 2020 Aug 15]. https://www.who.int/docs/default-source/coronaviruse/ situation-reports/20200814-covid-19-sitrep-207.pdf
2. State Control Room, Directorate of Public Health and Preventive Medicine Health and Family Welfare Department, Government of Tamil Nadu. Media bulletin 15.18.2020: daily report on public health measures taken for COVID-19 [cited 2020 Aug 15]. https:/ / stopcorona. tn.gov.in/wp-content/ uploads/2020/03/Media-Bulletin15-08-20-COVID-19-6-PM.pdf.

3. Greater Chennai Corporation. About Greater Chennai Corporation. [cited 2020 Sept 7]. https://www.chennaicorporation.gov.in/about-chennai-corporation/ aboutCOC.htm

4. Koopmans M, Haagmans B. Assessing the extent of SARS-CoV-2 circulation through serological studies. Nat Med. 2020;26:1171-2. https:/ / doi.org/10.1038/ s41591-020-1018-x

5. Murhekar MV, Bhatnagar T, Selvaraju S, Rade K, Saravanakumar V, Vivian Thangaraj JW, et al. Prevalence of SARS-CoV-2 infection in India: findings from the national serosurvey, May-June 2020. Indian J Med Res. 2020;152:4860. https://doi.org/10.4103/ijmr.IJMR_3290_20

6. SARS-CoV-2 IgG immunoassay. Instructions for use. Abbott. May 2020 [cited 2020 Sep 07]. https:/ / www.corelaboratory. abbott/us/en/offerings/segments/infectious-disease/ sars-cov-2

7. Special correspondent. Coronavirus: with over $65 \%$ of cases, all eyes on north Chennai. The Hindu. 2020 Apr 29 [citied 2020 Oct 26]. https:// www.thehindu.com/news/cities/ chennai/coronavirus-with-over-65-of-cases-all-eyes-onnorth-chennai/article31467330.ece

8. ICMR COVID Study Group; In alphabetical order: Abraham P, Aggarwal N, Babu GR, Barani S, Bhargava B, et al. Laboratory surveillance for SARS-CoV-2 in India: performance of testing \& descriptive epidemiology of detected COVID-19, January 22-April 30, 2020. Indian J Med Res. 2020;151:424-437. https:/ / doi.org/10.4103/ ijmr.IJMR_1896_20

9. Pollán M, Pérez-Gómez B, Pastor-Barriuso R, Oteo J, Hernán MA, Pérez-Olmeda M, et al. Prevalence of SARS-CoV-2 in Spain (ENE-COVID): a nationwide, population-based seroepidemiological study. Lancet. 2020396; 535-44. https:// doi.org/10.1016/S0140-6736(20)31483-5

10. Bogogiannidou Z, Vontas A, Dadouli K, Kyritsi MA, Soteriades S, Nikoulis DJ, et al. Repeated leftover serosurvey of SARS-CoV-2 IgG antibodies, Greece, March and April 2020. Euro Surveill. 2020;25:2001369. https:/ / doi.org/10.2807/1560-7917.ES.2020.25.31.2001369

11. Long QX, Liu BZ, Deng HJ, Wu GC, Deng K, Chen YK, et al. Antibody responses to SARS-CoV-2 in patients with COVID-19. Nat Med. 2020;26:845-8. https:/ / doi.org/ 10.1038/s41591-020-0897-1

12. Sekine T, Perez-Potti A, Rivera-Ballesteros O, Strålin K, Gorin JB, Olsson A, et al.; Karolinska COVID-19 Study Group. Robust $\mathrm{T}$ cell immunity in convalescent individuals with asymptomatic or mild COVID-19. Cell. 2020;183:158168.e14. https:// doi.org/10.1016/j.cell.2020.08.017

13. Ripperger TJ, Uhrlaub JL, Watanabe M, Wong R, Castaneda Y, Pizzato HA, et al. Orthogonal SARS-CoV-2 serological assays enable surveillance of low-prevalence communities and reveal durable humoral immunity. Immunity. 2020;53:925933.e4. https://doi.org/10.1016/j.immuni.2020.10.004

Address for correspondence: Manoj V. Murhekar, ICMR National Institute of Epidemiology, Second Main Road, Tamil Nadu Housing Board, Ayapakkam, Near Ambattur, Chennai 600077, Tamil Nadu, India; email: mmurhekar@nieicmr.org.in 